\title{
Role of Placental laterality as a Predictive Tool for Preeclampsia
}

\author{
Priyanka Ahuja ${ }^{1}$, Upma Saxena ${ }^{2}$, \\ ${ }^{1}$ Senior Resident, ${ }^{2}$ Professor\& Senior Gynecologist, Deptt of Obstetric and Gynecology, \\ VMMC \& Safdarjang Hospital, New Delhi- 110029,India
}

\begin{abstract}
Objective: To study role of Ultrasound determined placental laterality as a predictor of preeclampsia

Methods: This prospective study was conducted in the Department of Obstetrics and Gynaecology, VMMC \& Safdarjang Hospital, New Delhi from Feb 2019 to July 2019. Three hundred pregnant women attending antenatal clinic both OPD and IPD between 16 to 20 weeks of gestation without any high risk factor were subjected to ultrasound examination as a part of routine antenatal examination and placental location was determined. These cases were followed up for the development of preeclampsia.

Results :Out of the 300 women studied 241 had central placenta (Group A) and 59 had laterally located placenta (group B). Out of 59 women with lateral placenta, 29 (49.2\%) developed preeclampsia while out of the 241 women with central placenta only 19 (7.88\%) developed preeclampsia. This was statistically significant ( $\mathrm{p}$ value $<0.0001$ ). The sensitivity, specificity, positive predictive value and negative predictive value of placental laterality as a predictor for preeclampsia was $64.18 \%, 83.19 \%, 53.16 \%$ and $88.64 \%$ respectively.
\end{abstract}

Conclusion: Placental laterality by ultrasound d at 16-20 weeks; is a simple, cheap and effective method ,establishing its role as early predictor of pre-eclampsia.

Keyword: preeclampsia, placental laterality, predictor,sonography

\section{Introduction}

Pre-eclampsia, is still the most common medical complication of pregnancy. Women with mild and moderate degrees of gestational hypertension can often be treated conservatively and be delivered at or near term with good perinatal outcome. However severe pre-eclampsia developing in late second or early third trimester is associated with a marked increase in perinatal morbidity and mortality. ${ }^{1}$

\section{Corresponding Author}

Upma Saxena,

Professor\& Senior Gynecologist, Address: M-14 (Residence) Greater Kailash Part 2,

New Delhi -110048, India.

email:upma_saxena@hotmail.com

TEL:09971460540
It has been seen and proved that in humans both uterine arteries have a significant anastomoses and branches and that each supply the corresponding side of the uterus. In the women with a centrally located placenta both the arteries have demonstrated equal resistance. However, when the placenta is located laterally the uterine artery closer to the placenta has lower resistance than the one opposite to it and in majority of cases the uteroplacental blood flow needs are primarily met by one of the uterine arteries .

The degree of collateral circulation may not be the same in all women and deficit contribution may facilitate the development of preeclampsia or FGR or both. This may explain the reduced trophoblastic invasion in laterally situated placenta when the utero placental blood supply needs are mainly met by one side uterine artery leading to $\mathrm{PE}{ }^{2}$ 
Various screening tests have been proposed for the prediction of preeclampsia with varying results. Some of these tests have shown a potential as practical early screening test for the prediction of preeclampsia and related complications of pregnancy. ${ }^{3}$

Most women with pregnancy induced hypertensive disorder are symptomless, which is an important part of the rationale for frequent antenatal visits in late pregnancy. An increased diastolic blood pressure or increased second trimester mean arterial pressure just predicts gestational hypertension, not preeclampsia which is associated with maximal perinatal morbidity and mortality. ${ }^{4,5}$

Weight gain also cannot predict development of pregnancy induced hypertension and excess weight gain alone does not adversely affects the outcome.$^{5}$

Proteinuria is a late sign of pregnancy-induced hypertensive disorders and HELLP syndrome and eclampsia could occur in the absence of proteinuria. After blood pressure measurement, dipstick proteinuria analysis is the most common screening test for preeclampsia. ${ }^{6}$

Poor sensitivity and specificity and the fact that proteinuria is such a late feature of the disease make routine use of dipsticks in a normotensive low risk population just as ineffective in predicting pre-eclampsia as measuring maternal weight gain . ${ }^{7}$

However the dipstick is easy to use and cheap, and assists in timely diagnosis of pre-eclampsia, especially in those patients with borderline increase in blood pressure and in patients at a higher risk e.g. with that of chronic hypertension. ${ }^{8}$

Women with raised second trimester maternal serum-fetoprotein (MSAFP) concentration whose fetuses do not have neural tube defects have been found to be at increased risk of fetal death, delivery of an infant who is small for gestational age and preterm delivery. ${ }^{9}$

Platelet lifespan is much shorter in pregnancyinduced hypertensive disorders, particularly when complicated by fetal growth retardation. But there is a huge overlap between the distribution of platelet count in normotensive and pregnant women with hypertension thus it is not effective. ${ }^{10}$

Impaired trophoblast invasion is one of the key features of preeclampsia and most cases of FGR. It has been observed that uterine artery Doppler assessment has limited ability to screen for pre-eclampsia. However, an abnormal Doppler result increases the likelihood of preeclampsia six-fold. ${ }^{11}$

Early prediction can help in start of simple strategy like low dose aspirin which has proven benefit in lowering the severity of disease and increase in fetal weight. ${ }^{12}$ Hence, multifactorial origin of pre-eclampsia makes it is highly unlikely that there will be one universal predictive test in the future.

The objective of our study was to analyze the efficacy of the placental laterality using ultrasonography at 16-20 weeks in predicting women at risk of developing pre-eclampsia. However, other parameters can also be combined with placental laterality, improving the sensitivity and specificity for prediction of PE.

\section{Method}

A prospective study was conducted at the Department of Obstetrics and Gynaecology, VMMC \& Safdarjang Hospital, New Delhi from February 2019 to July 2019. Three hundred pregnant women attending antenatal clinic both OPD and IPD between 16 to 20 weeks of gestation were included in the study and subjected to Transabdominal ultrasonography .

Based on the location of placenta they were divided into two groups: Group A included the women with centrally located placenta (placenta distributed equally or almost equally between the right and left side of the uterus, irrespective of anterior/posterior and fundal location) while women with lateral placenta (where $70 \%$ or more of the placenta was on either side of the midline, irrespective of anterior, posterior or fundal location) were put in Group B.

These women were then followed up for development of Pre-eclampsia and were delivered at our hospital. Results of placental localization on sonography were then co-related with the development of preeclampsia as per the ACOG 2013 criteria.

\section{Results}

Out of 300 antenatal women studied 129 (43\%) were primigravida and 171 (57\%) were multigravida. Women were divided into two groups according to the location of placenta. Two hundred forty one $(80.3 \%)$ women had a centrally located placenta and hence belonged to group A and only 59(19.67\%) with laterally located placenta 
belonged to group B. Out of 300 women studied ,48 $(16 \%)$ developed preeclampsia .

Out of 59 women with laterally located placenta, 29(49.2\%) developed preeclampsia while in women with 241 with centrally located placenta only $19(7.88 \%)$ developed preeclampsia. (Table 1) So, 29/48 (60.4\%) women developing preeclampsia had a laterally situated placenta while 19/48 (39.6\%) had a centrally situated placenta $(\mathrm{p}<0.001)$.

Out of the 252 women who did not develop preeclampsia $222(88.1 \%)$ had a centrally located placenta while only $30(11.90 \%)$ women had a laterally situated placenta. $(\mathrm{p}<0.001)$
After combining the variables of age, parity and lateral location of placenta , $87.5 \%$ of the primigravida with lateral location of the placenta below 20 years developed preeclampsia .(Table 2) The primigravida at extremes of ages having lateral placenta on ultrasound clearly were at higher risk of developing preeclampsia. Hence, on combining parity with age and placental location the sensitivity of the predictive value for $\mathrm{PE}$ was increased.

In Multigravidas it was observed that $66 \%$ women with lateral placenta and age $>30$ years developed preeclampsia. (Table 3) The sensitivity, specificity, positive predictive value, negative predictive value of only placental laterality were $64.18 \%, 83.19 \%, 53.16$, $\%, 88.64 \%$ respectively.

Table 1: Placental Laterality as predictor of Pre-eclampsia

\begin{tabular}{|l|l|l|l|}
\hline Location of placenta & Preeclamsia developed & $\begin{array}{l}\text { Preeclamsia } \\
\text { Not developed }\end{array}$ & Total \\
\hline Central (group A) & 19 & 222 & $241(80.33)$ \\
\hline Lateral (group B) & 29 & 30 & $59(19.67)$ \\
\hline Total & $48(16 \%)$ & $252(84 \%)$ & 300 \\
\hline
\end{tabular}

Table: 2 Parity, age and lateral location of placenta as predictors for preeclampsia in primigravidas.

\begin{tabular}{|l|l|l|l|l|l|}
\hline & $<\mathbf{2 0}$ & $\mathbf{2 1 - 2 5}$ & $\mathbf{2 6 - 3 0}$ & $>\mathbf{3 0}$ & Total \\
\hline Total women in group A & 28 & 54 & 17 & 3 & $\mathbf{1 0 2}$ \\
\hline Women with preeclampsia (group A) & $1(3.5 \%)$ & $5(9.2 \%)$ & $3(17.64)$ & 0 & $9(8.73 \%)$ \\
\hline Total women in group B & 8 & 12 & 7 & 0 & $\mathbf{2 7}$ \\
\hline Women with preeclampsia (group B) & $7(87.5 \%)$ & $6(50 \%)$ & $5(71.4 \%)$ & 0 & $18(66.67 \%)$ \\
\hline
\end{tabular}

Table 3: Parity, age and lateral location of placenta as predictors for preeclampsia in multigravidas .

\begin{tabular}{|l|l|l|l|l|l|}
\hline & $<\mathbf{2 0}$ & $\mathbf{2 0 - 2 5}$ & $\mathbf{2 6 - 3 0}$ & $>\mathbf{3 0}$ & Total \\
\hline Total women in group A & 7 & 75 & 40 & 17 & 139 \\
\hline $\begin{array}{l}\text { Women with preeclampsia } \\
\text { (group A) }\end{array}$ & 0 & $6(8.1 \%)$ & $3(7.5 \%)$ & $1(5.8 \%)$ & $10(7.97 \%)$ \\
\hline Total women in group B & 2 & 18 & 9 & 3 & 32 \\
\hline $\begin{array}{l}\text { Women with preeclampsia } \\
\text { (group B) }\end{array}$ & 0 & $5(27.77 \%)$ & $3(33.33 \%)$ & $2(66 \%)$ & $11(34.37 \%)$ \\
\hline
\end{tabular}




\section{Discussion}

Pre-eclampsia is one of the leading causes of maternal and also perinatal mortality and morbidity. We thus need a test that could predict high risk of developing PE in pregnancy, so that prophylactic therapy could be started early. An ideal screening test should be simple, reproducible and inexpensive, with a high sensitivity and positive predictive value, and it should also be easy to perform and non-invasive.

In the present study, women developing preeclampsia had laterally situated placenta in $60.4 \%$ which was statistically significant. The sensitivity and specificity of placental laterality in predicting PE was much higher in primigravida and women in younger age group. This observation was similar to a study where PE developed in $80.7 \%$ women with laterally located placenta and primigravidas had a significantly higher probability of developing PE compared to multigravida. ${ }^{13}$

In a study conducted in Manipur, $17.1 \%$ of laterally located placenta developed preeclampsia while only $6.1 \%$ of centrally located developed preeclampsia. ${ }^{14}$

After combining the variables of age, parity and lateral location of placenta in the present study, $87.5 \%$ of the primigravida with lateral location of the placenta below 20 years developed preeclampsia which is comparable to a study in which also, maximum women who developed PE were in the age group of 21-25 years followed by 30 years. ${ }^{15}$

The sensitivity of placental laterality for predicting PE $(64.18 \%)$ in the present study was comparable to study by Kofinas et al in which the sensitivity for predicting PE was $73 \% .^{16}$

In the present study when placental laterality was clubbed with other risk factors like primiparity and extremes of maternal age, the sensitivity was much higher with a good specificity and negative predictive value which was similar to another study by Dekker and Sibai. ${ }^{17}$

The sensitivity, specificity, positive predictive value and negative predictive value of $59.38 \%, 88.10 \%$, $48.72 \%$ and $91.93 \%$ respectively was comparable to a study where it was $73 \%, 86 \%, 51 \%$ and $94 \%$ respectively. In this study the also sensitivity and specificity was much higher in primigravida and women belonging to younger age group. ${ }^{18}$
In the present study the sensitivity of placental laterality was $64.18 \%$ which was low but is much better than most other tests ie. Urine albumin/ creatinine ratio, handgrip test, abnormal RI on Doppler and mid trimester BP which had sensitivity of $64 \%, 81 \%, 47 \%$ and $44 \%$ respectively. Also the negative predictive value, specificity were also much higher compared to these tests. ${ }^{18}$

As yet there is no practical, acceptable and reliable screening test for preeclampsia that has been thoroughly tried and tested. Though in last two decades, uterine artery Doppler velocimetry has been advocated as an effective screening method, but it requires expertise, is costly and not easily available.

On the other hand majority of pregnant women undergo sonography at 16-20 weeks in order to rule out gross congenital anomalies and placental localization in the same setting does not add to the cost of the procedure. Thus diagnosis of placental laterality is non-invasive, easy to perform, and available and cheap test for early prediction of PE.

\section{Conclusion}

Placental laterality as determined by the ultrasound at 16-20 weeks; alone or with age and parity is a simple and cost effective test for prediction of PE which can be utilized in all pregnant women attending the antenatal clinic.

\section{Source of Funding -Self}

Compliance with Ethical requirement - Yes

\section{Conflict of Interest -Nil}

\section{References}

1) Kore SJ, Khot R. Prediction of pre-eclampsia: role of placental laterality by ultrasonography. Int J Repod Contracept Obstet Gynecol. 2016 (May5);(5):1433-1437.

2) Sumathi N, Pavithra GR. Placental Laterality-A simple yet reliable predictor of preeclampsia an ultrasonic prospective study.IOSR-JDMS.2016 (October 2016);15(10):116-121.

3) Sibai BM .First-trimester screening with combined maternal clinical factor, biophysical and biomarkers to predict preterm pre-eclampsia and hypertensive disorder: are they ready for clinical use? BJOG. 2015; 122(3): 282-3. 
4) Villar MA, Sibai BM .Clinical significance of elevated mean arterial blood pressure in second trimester and threshold increase in systolic or diastolic blood pressure during the third trimester. Am J ObstetGynecol.1989; 160: 419-23.

5) Conde-Agudelo A, Balizan JM, Lede R, Bergel EF. What does an elevsted mean arterial pressure in second half of pregnancy predict:gestational hypertension or preeclampsia?.Am J ObstertGynecol. 1993; 169:509-14.

6) Masse J, Forest J-C, Moutquin J-M, Marcoux S,Brideau N-A, Belanger M. A Prospective study of several potential biologic markers for early prediction of preeclampsia. Am J Obstet Gynecol. 1993; 169: 501-08.

7) Halligan AW, Bell SC, Taylor DJ .Dipstick proteinuria: caveat empyor. $\mathrm{Br} \mathrm{J}$ Obstet Gynecol.1999;106:1113-15.

8) Dawes MG, Grudzinskas JG.Repeated measurement of maternal weight during pregnancy: is this a useful practice? .Br J Obstet Gynaecol.1991; 98: 189-94.

9) Van Rijn M, van der Schouw YT, Hagenaars AM, Visser GHA, Christiaens GC. Adverse obstetric outcome in low and high risk pregnancies: predictive value of maternal serum screening. Obstet Gynecol.1999;94:929-34.

10) Halligan A, Bonnar J, Sheppard B, Darling M, Walshe J .Haemostatic, fibrinolytic and endothelial variables in normal pregnancies and pre-eclampsia. Br J Obstst Gynaecol. 1994; 101:4888-92.
11) $\mathrm{K}$ Harrington et al.Transvaginal Doppler ultrasound of the uteroplacental circulation in the early prediction of pre-eclampsia and intrauterine growh retardation.Br J Obstet Gynaecol. 1997 (Jun 1997);104(6):674-81.

12) Knight $M$ et al.Antiplatelet agents for preventing and treating preeclampsia.km Cochrane database syst rev. 2000;(2):CD000492

13) Sumathi.N ,Pavithra GR.Placental Laterality-A Simple yet reliable predictor of preeclampsia an ultrasonic prospective study. IOSR-JDMS.2016 (October 2016);15(10):116-121.

14) Aggarwal.P, Kangjam.P,Terhase.N.Study on relation between placental laterality in second trimester ultrasound and development of preeclampsia at term. JEMDS.2015 (December 2015);4(104):16926-16928.

15) Kakkar T,Singh V,Razdan R,Digra S,Kakkar M.Placental laterality as a predictor for development of preeclampsia.JOGI.2013(March 2013);63(1):22-25.

16) Kofinas AD, Penry M, Swain M, Hatjis CG. Effect of placental laterality on uterine artery resistance and development of preeclampsia and intra uterine growth retardation .Am J Obstet Gynecol. 1989; 161:153-69.

17) Dekker G, Sibai B .Primary, secondary and tertiary prevention of pre-eclampsia. Lancet. 2001; 357: 209-15.

18) Chan FY, Pun TC, Lam C, Khoo J, Lee CP, Lam YH .Pregnancy screening by uterine artery Doppler velocimetry-which criterion performs best? ObstetGynecol. 1995; 85:596-602. 